\title{
Cerebral Hemorrhage and Femoral Neck Fracture as Initial Presentations of Hepatocellular Carcinoma
}

\section{Patanee O'Charoen, MD.}

Division of Radiology, Bangkok Metropolitan Administration General Hospital, Department of Medical Services, Bangkok Metropolitan Administration, Pomprap, Pomprapsattrupai, Bangkok 10110, Thailand

\begin{abstract}
Hepatocellular carcinoma (HCC) is the most common primary liver tumor and one of the most common causes of cancer-related death in Thailand, particular in male. Extrahepatic metastases are common but usually diagnosed after detection of HCC. These reported cases presented with cerebral hemorrhage and femoral neck fracture which are rare initial presentations of HCC.
\end{abstract}

\section{Introduction}

Hepatocellular carcinoma (HCC) is the most common primary liver tumor and one of the most common causes of cancer-related death worldwide, particular among males in Asia-Pacific region including Thailand. ${ }^{1-5}$ This may be related to high prevalence of hepatitis $B$ virus and hepatitis $C$ virus nfections in this region. ${ }^{6} \mathrm{HCC}$ is a devastating tumor known for its propensity to directly invade the portal and hepatic veins, but lymphatic and distant metastases are not rare, especially in tumors greater than $5 \mathrm{~cm}^{7}$ Extrahepatic metastases are seen in $13-64 \%$, and common metastatic sites are lungs, lymph nodes, bones and adrenal glands, respectively. ${ }^{8-11}$ Brain metastasis from HCC is extremely rare with a reported frequency ranging from 0.2$2.2 \%$, with utterly poor prognosis. ${ }^{12-15}$ Bone metastasis is commonly seen in the vertebrae. ${ }^{9.16,17}$ It is usually diagnosed after detection of HCC, and rarely developed pathological fracture as the first clinical manifestation. ${ }^{17-21}$

\section{Case reports}

Case I : Thai male presented with left hemiparesis. CT scan of the brain revealed a $4 \mathrm{~cm}$ round 

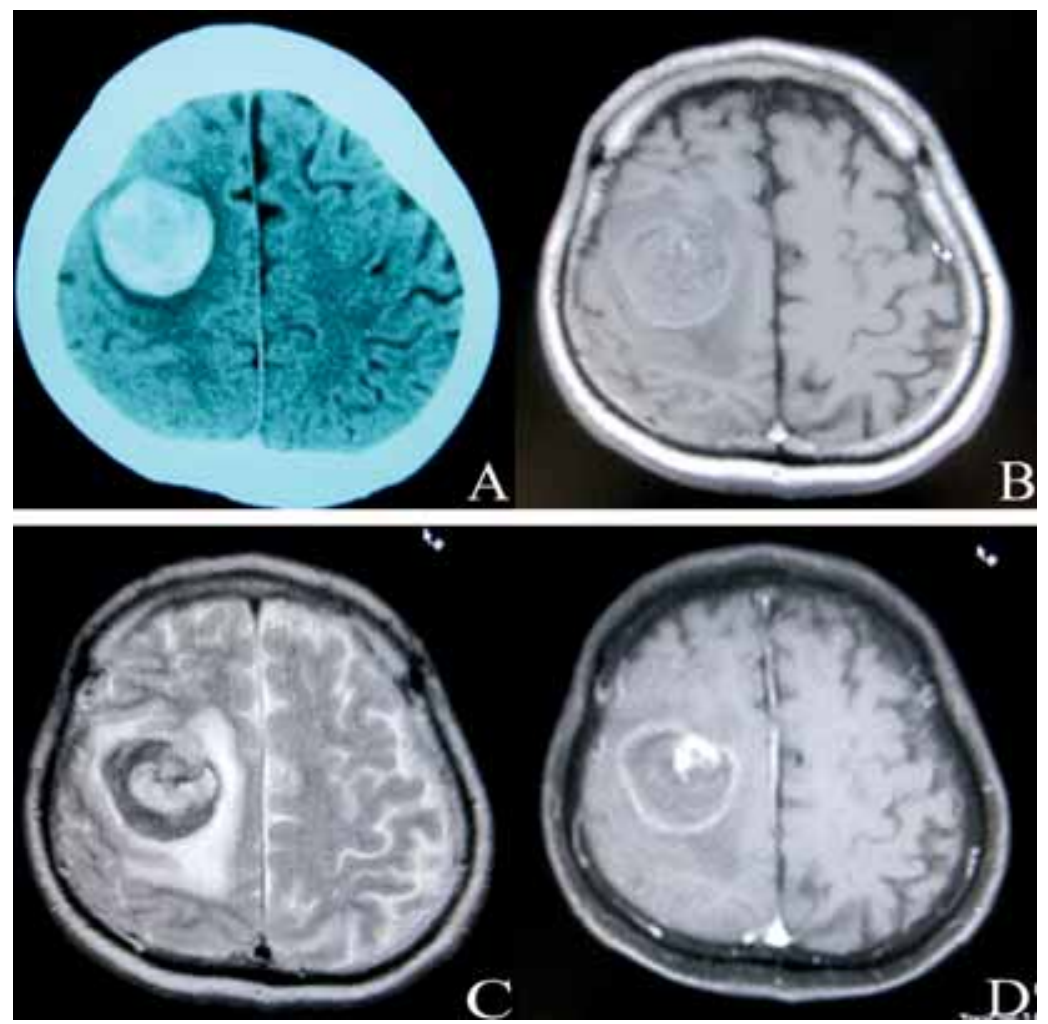

Fig 1. Axial CT scan of the brain $(A)$ revealed a $4 \mathrm{~cm}$ round hyperdense lesion at right high frontal lobe. The lesion showed mostly iso SI on T1-weighted image (B), mixed SI on T2-weighted image (C) and enhancement after gadolinium administration (D). Perilesional edema is evident.

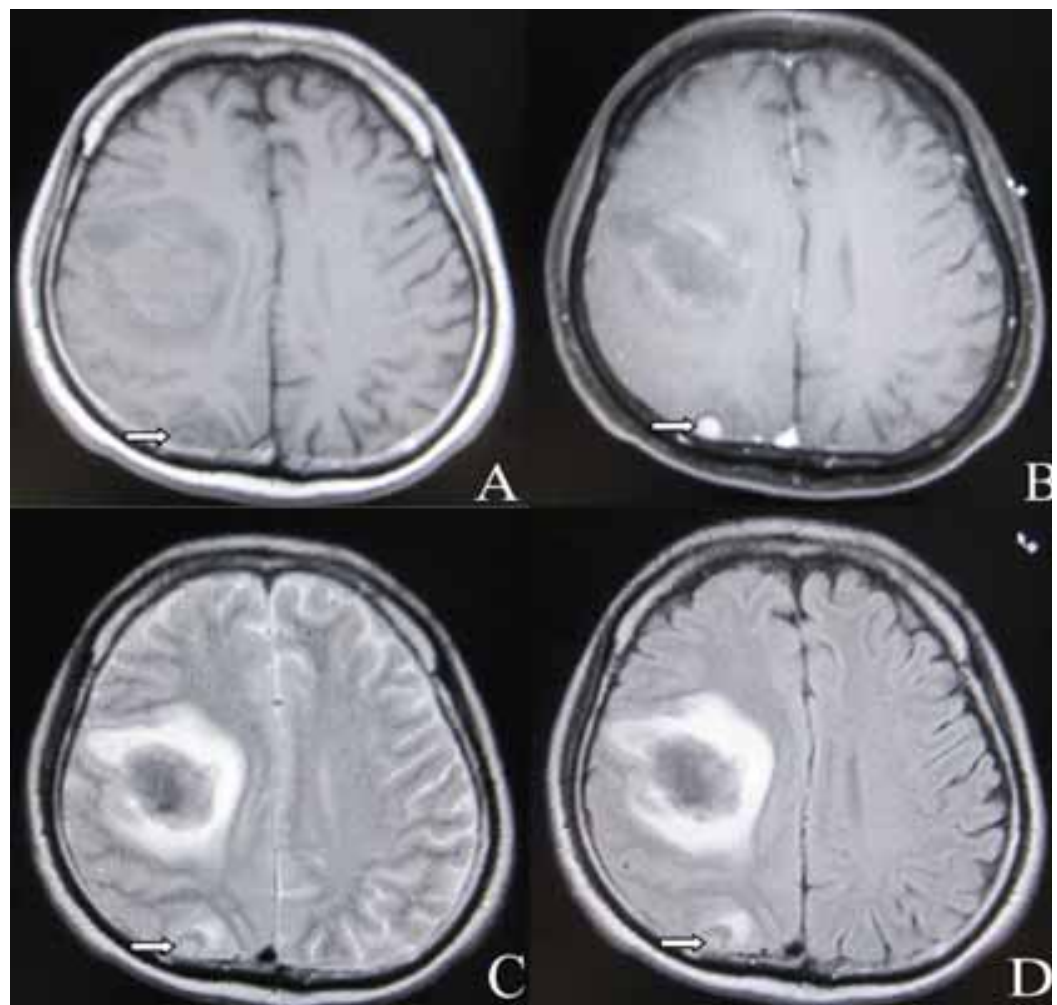

Fig 2. Axial $\mathrm{T} 1$-weighted image $(\mathrm{A})$, post gadolinium $\mathrm{T} 1$-weighted image with fat saturation $(\mathrm{B})$, $\mathrm{T} 2$ - weight image $(\mathrm{C})$, and FLAIR (D) demonstrated a $0.8 \mathrm{~cm}$ round lesion at posterior aspect of right parietal lobe (arrows) showing same $\mathrm{SI}$ as the large lesion in right frontal lobe with homogeneous enhancement and surrounding edema. 


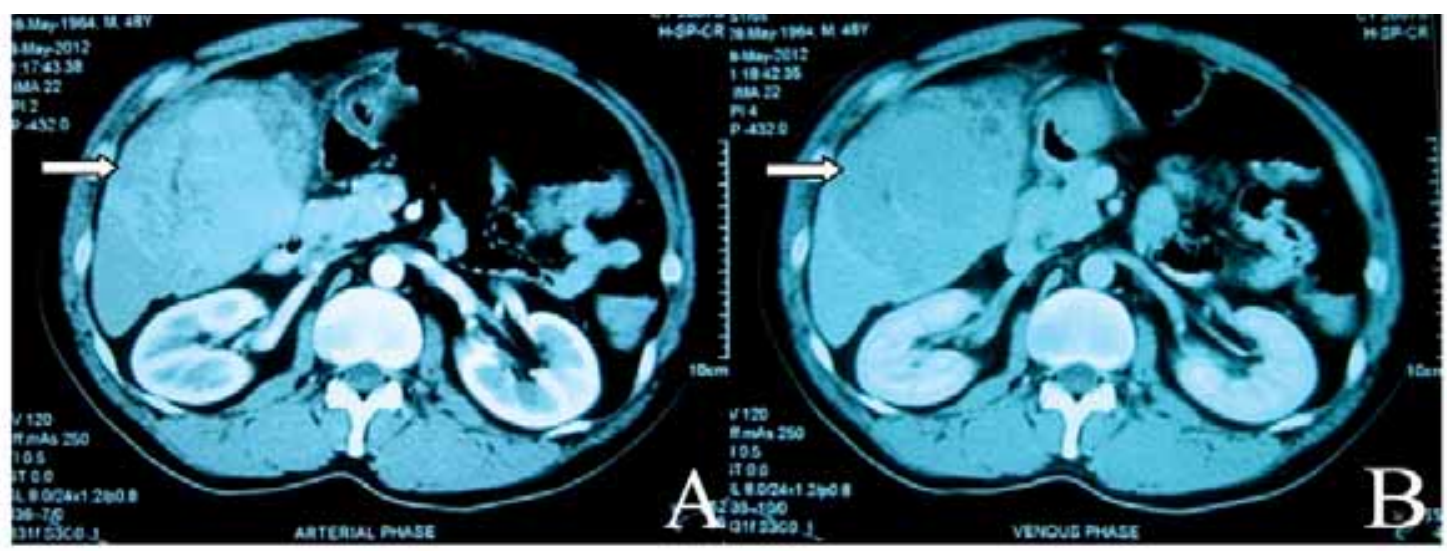

Fig 3. Post-contrasted CT scan of the abdomen, arterial phase (A) and venous phase (B) revealed a large mass at right hepatic lobe showing arterial enhancement and rapid washout (arrows).

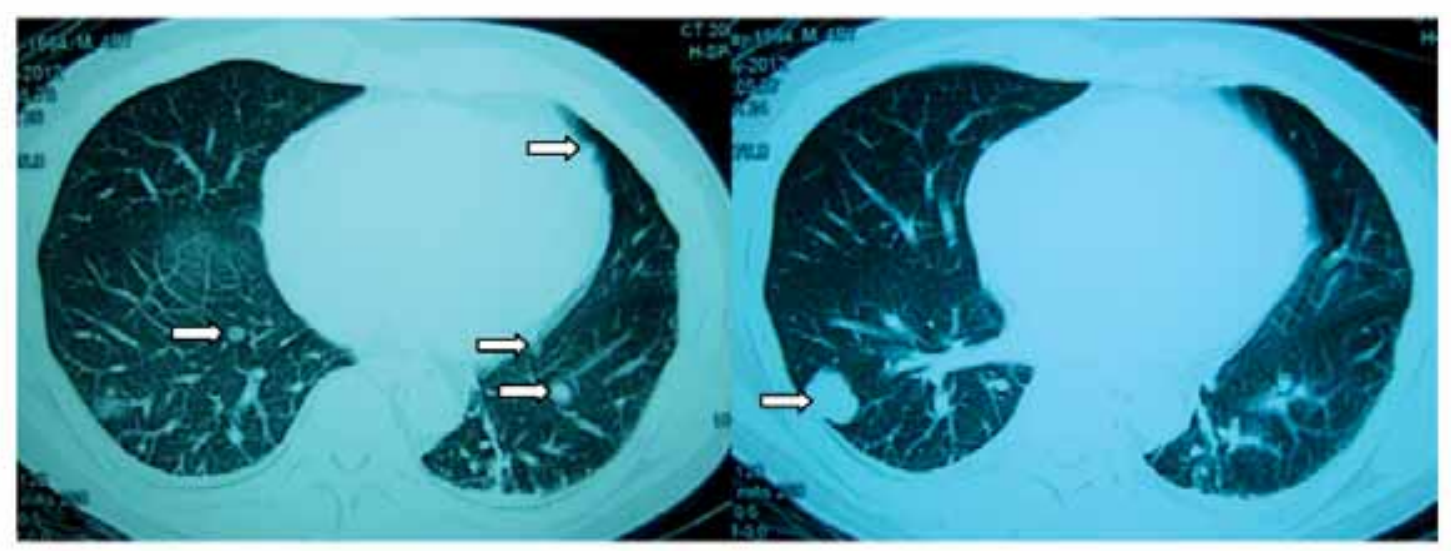

Fig 4. CT scan of the chest showed multiple nodules in both lungs (arrows).

hyperdense lesion with perilesional edema at right high frontal lobe consistent with hemorrhage (Fig 1A). MRI of the brain (Fig 1B-D) showed a $4 \times 3.3 \mathrm{~cm}$ lesion at right high frontal lobe showing slightly low signal intensity (SI) on T1-weighted image, dark SI on T2-weighted image, FLAIR and gradient echo image with areas of high SI at anteromedial aspect, rim enhancement and small area of enhancement at anterior aspect. Marked surrounding edema was observed causing effacement of adjacent cortical sulci and midline shift to the left about $0.4 \mathrm{~cm}$. There was a $0.8 \mathrm{~cm}$ round lesion at posterior aspect of right parietal lobe showing same SI with intense homogeneous enhancement and mild sur- rounding edema (Fig 2). These two lesions were considered hemorrhagic metastases.

Laboratory findings showed positive HBsAg, Anti HBs, Anti HBc, Anti HCV, and negative HBeAg. Tumor markers were as following : AFP 5268 (0-7.02) ng/ml, PSA 0.51 (0.59-2.0) ng/ml, CA19-9 102.40 (0-37) U/ml, CA125 84.41 (0-35) U/ml, CEA $4.62(0-4.6) \mathrm{ng} / \mathrm{ml}$.

CT scan of the abdomen revealed multiple hepatic masses showing arterial enhancement and rapid washout. The largest mass was in right hepatic lobe (Fig 3). CT scan of the chest showed multiple nodules in both lungs consistent with pulmonary metastases (Fig 4). 


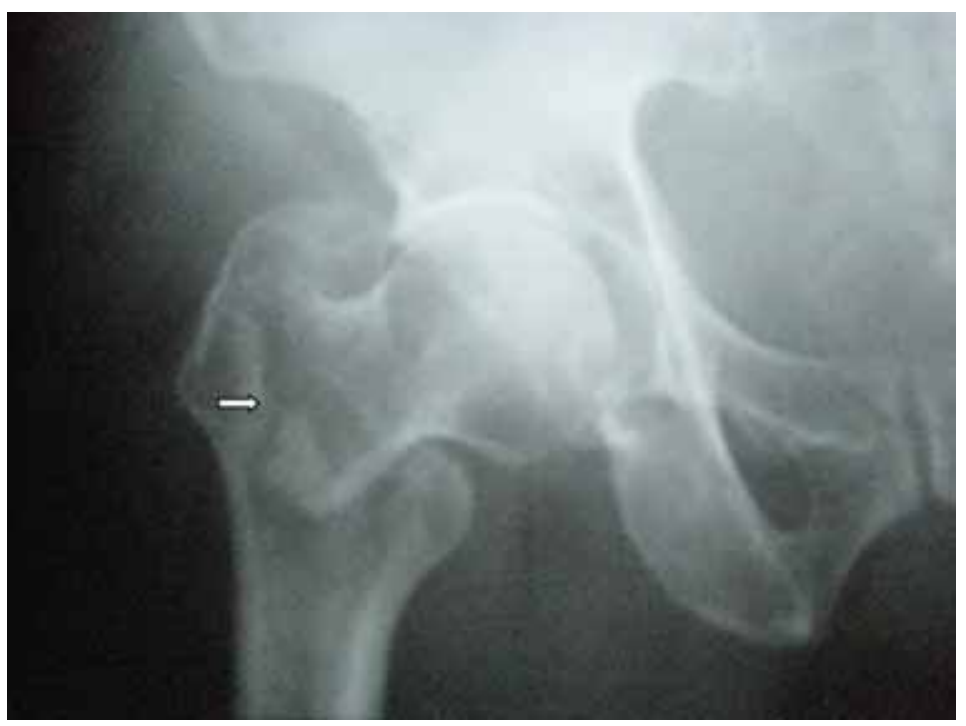

Fig 5. Plain radiograph of right hip revealed osteolytic lesion at femoral neck with pathologic fracture (arrow).

Right frontal parasagittal craniotomy with clot and tumor removal was performed. Pathological and immunohistochemical report showed metastatic adenocarcinoma and the most possible diagnosis was HCC. Patient received whole brain radiation after surgery and the patient died a few months later.

Case II : A 55-year-old, Thai male presented with right hip pain after sound at right hip while wearing slacks for 2 weeks. He has underlying diabetes mellitus and hypertension. Plain radiograph of right hip revealed osteolytic lesion at femoral neck with pathologic fracture (Fig 5). Hemiarthroplasty of right hip was performed and pathology revealed anaplastic cells in organoid patterns, suggesting $\mathrm{HCC}$.

Laboratory findings revealed RBC 2.53x 1,000,000/mm $\mathrm{mm}^{3}$, Hb $8.1 \mathrm{~g} / \mathrm{dl}$, Hct 23.2\%, WBC 12.8 $\mathrm{x} 1,000 / \mathrm{mm}^{3}$ (neutrophil $78.1 \%$, lymphocyte $10.9 \%$, monocyte $9.2 \%$, eosinophil $0.9 \%$, basophil $0.9 \%$ ), platelet count $641,000 / \mathrm{mm}^{3}$, total protein $7.0(6-8)$ g/dl, albumin 3.0 (3.5-5.6) g/dl, globulin 4.0 (1.3-3) $\mathrm{g} / \mathrm{dl}$, total bilirubin $1.44(0-1.5) \mathrm{mg} / \mathrm{dl}$, direct bilirubin $0.27(0-0.5) \mathrm{mg} / \mathrm{dl}$, indirect bilirubin $1.17(0-1) \mathrm{mg} /$ dl, AST 72 (0-35) U/L, ALT 23 (0-43) U/L, alkaline phosphatase 406 (39-117) U/L, Anti HIV-non reactive, CEA 9.04 (0-4.6) ng/ml, CA 19-9 152 (0-37) $\mathrm{U} / \mathrm{ml}$, AFP $70.24(0-7.02) \mathrm{ng} / \mathrm{ml}$, PSA 0.334 (0.753.1) $\mathrm{ng} / \mathrm{ml}$.

He developed ascites and right leg edema after operation. Ultrasonography of abdomen was performed and revealed heterogeneously increased parenchymal echo of the liver with a $6.4 \times 4.9 \times 4.8$ $\mathrm{cm}$ hyperechoic mass with central low echo at left hepatic lobe (Fig 6) and ascites. CT scan of whole abdomen demonstrated hepatic cirrhosis with a $5.8 \times 4.3 \mathrm{~cm}$ mass with central necrosis at left lobe (Fig 7). Right portal vein thrombosis with cavernous transformation was observed. Moderate ascites and minimal right pleural effusion were seen.

Patient readmitted with anemia, abdominal distension, infected wound and electrolyte imbalance, and died two months after surgery. 


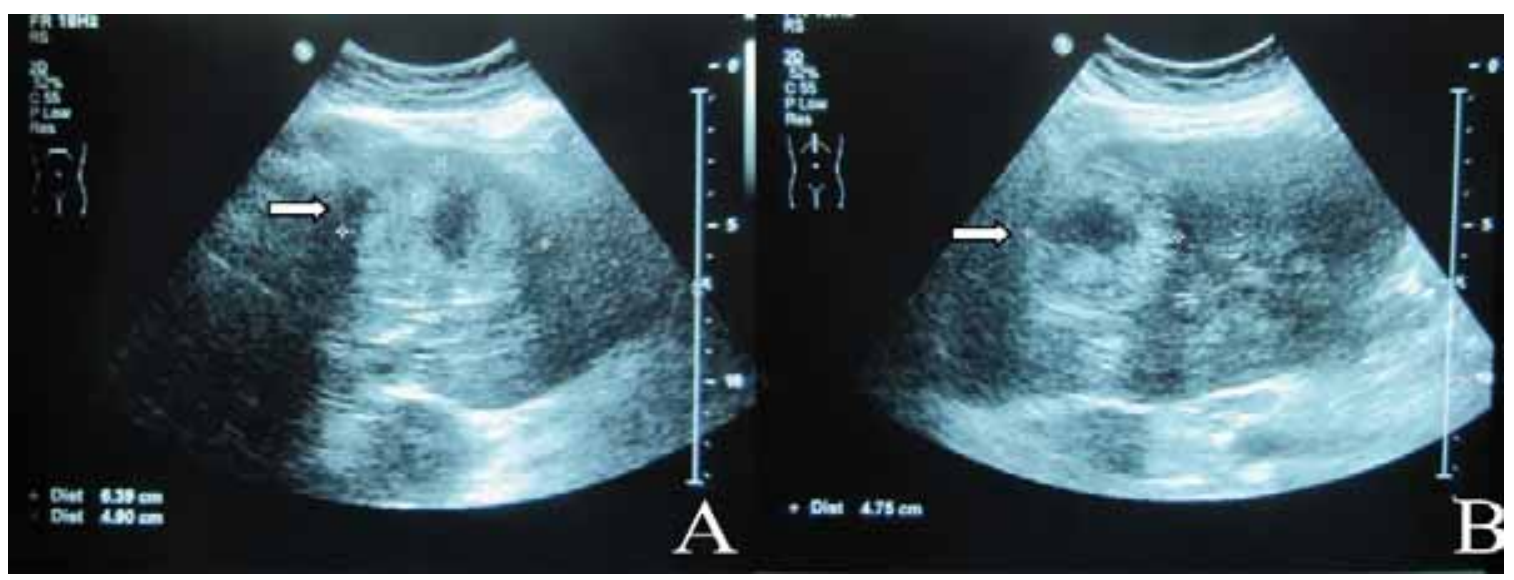

Fig 6. Ultrasonograpphy of abdomen, axial (A) and sagittal (B) showed heterogeneously increased parenchymal echo of the liver with a $6.4 \times 4.9 \times 4.8 \mathrm{~cm}$ hyperechoic mass with central low echo at left hepatic lobe (arrow)

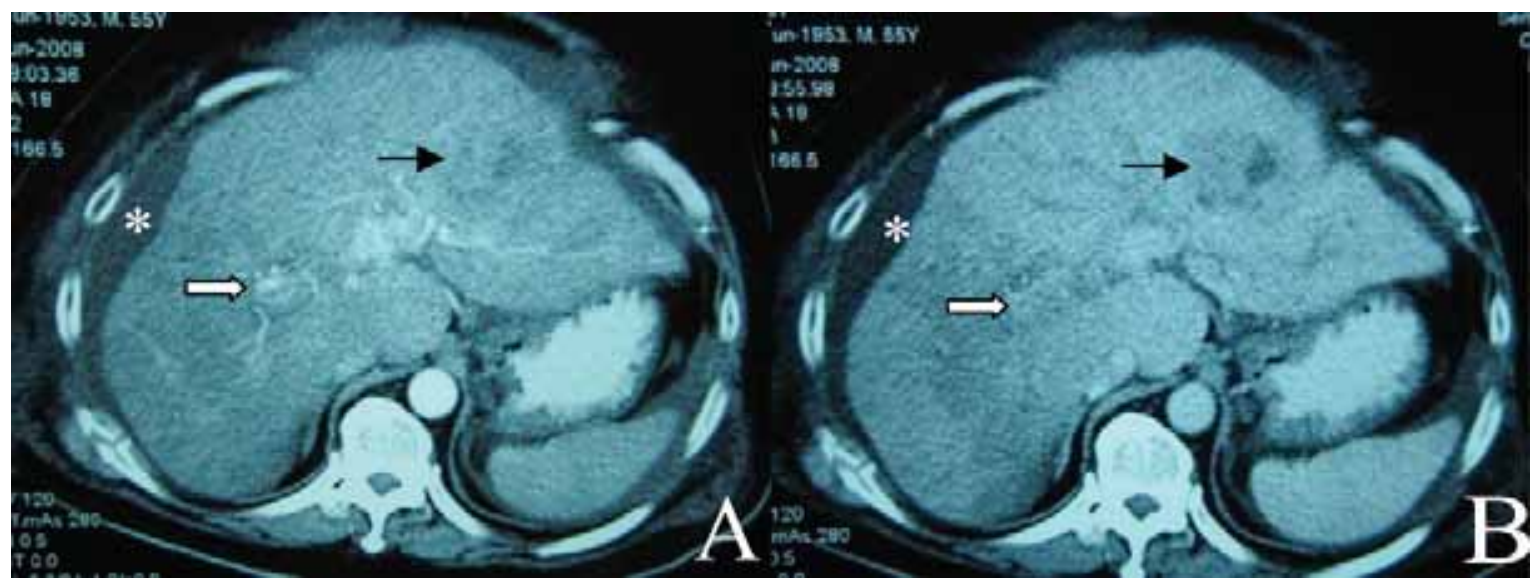

Fig 7. Post-contrasted CT scan of abdomen, arterial phase (A) and venous phase (B) revealed a mass at left hepatic lobe showing arterial enhancement with rapid washout and central necrosis (black arrows). Right portal vein thrombosis with cavernous transformation is shown (white arrows) with heterogeneous enhancement of hepatic parenchyma. Ascites is visualized $\left({ }^{\star}\right)$.

\section{Discussion}

HCC is still a fatal disease possibly associated with the advanced stage at which the disease is usually diagnosed. ${ }^{411}$ HCC spreads locally and metastasizes distally by hematogenous and lymphatic routes. Common metastatic sites are lungs, regional lymph nodes, bones and adrenal glands. Brain and bone metastases as the initial manifestations are extremely rare.
Most of the brain lesions showed hyperdensity on non-contrasted computed tomography and homogeneous enhancement after contrast material administration, with perifocal edema. Some presented with intracerebral hemorrhage and some had skull involvement. ${ }^{14,22}$ The reported Case I manifested with intracerebral hemorrhage with perifocal edema, without skull involvement.

There was no survival difference according to 
gender, age, control of HCC, liver function, levels of AFP, CEA and CA19-9, hepatitis virus B infection, intracranial hemorrhage, location and number of brain lesions, and interval between diagnosis of HCC and brain metastasis. ${ }^{12}$ Bone metastases from HCC ranged from $3 \%$ to $20 \%{ }^{17}$ The incidence of $\mathrm{HCC}$ with bone metastasis at the time of initial diagnosis was around $5 \% .^{20}$ The most common sites of bone metastases were the vertebra, followed by the pelvis, rib and skull. ${ }^{17}$ All the lesions were osteolytic type. $^{8,9,17-21}$ The reported Case II presented with osteolytic lesion at femoral neck and pathological fracture.

In conclusion, brain metastases from HCC are fairly rare and it is even rare to find them as initial manifestation of HCC. Although bone metastasis is not uncommon but it is also rare to find bone metastasis as the first overt manifestation of HCC. The reported cases presented with cerebral hemorrhage and fracture femoral neck as initial manifestations of HCCs, thus, patients present with osteolytic bone lesions or hemorrhagic brain metastases, HCC should be included in the differential diagnosis, particular in Thai male.

\section{References}

1. Jemal A, Ward E, Hao Y, Thun M. Trends in the leading causes of death in the United States, 1970- 2002. JAMA 2005 Sep;294(10):1255-9.

2. Bosch FX, Ribes J, Diaz M, Cleries R. Primary liver cancer: worldwise incidence and trends. Gastroenterology 2004 Nov;127(5 suppl):S5-S16.

3. Srivatanakul $P$, Sontipong $S$. Incidence of liver cancer in Thailand 1979. Thai Cancer J 1979;8:127-34.

4. Kassianides C, Kew MC. The clinical manifestations and natural history of hepatocellular carcinoma. Gastroenterol Clin N Am 1987 Dec;16(4):553-62.
5. Jemal A, Bray F, Center MM, Ferlay J, Ward E, Forman D. Global cancer statistics. CA Cancer J Clin 2011 MarApr;61(2):69-90.

6. Perz JF, Armstrong GL, Farrington LA, Hutin YJ, Bell BP. The contritutions of hepatitis $B$ and hepatitis $C$ virus infections to cirrhosis and primary liver cancer worldwide. J Hepatol 2006 Oct;45(4):529-38.

7. Yuki K, Hirohashi S, Sakamoto M, Kanai T, Shimosato Y. Growth and spread of hepatocellular carcinoma. Cancer 1990 Nov;66(10):2174-9.

8. Sneag DB, Krajewski K, Giardino A, O’Regan KN, Shinagare $A B$, Jagannathan JP, Ramaiya N. Extrahepatic spread of hepatocellular carcinoma: Spectrum of imaging findings. AJR 2011 Oct;197(4):W658-64.

9. Katyal S, Oliver JH $3^{\text {rd }}$, Peterson MS Ferris JV, Carr BS, Baron RL. Extrahepatic metastasis of hepatocellular carcinoma. Radiology 2000 Sep;216(3):698-703

10. Tang ZY. Hepatocellular carcinoma-cause, treatment and metastasis. World J Gastroenterol 2001 Aug;7(4):445-54.

11. Sithinamsuwan P. Peratvisuth T, Tanomkiat W, Apakupakul N, Tongyoo S. Review of 336 patients with hepatocellular carcinoma at Songklanagarind Hospital. World J Gastroenterol 2000 June;6(3):339-43.

12. Jiang XB, Ke C, Zhang GH, Zhang XH, Sai K, Chen ZP, Mou YG. Brain metastases from hepatocellular carcinoma: clinical features and prognostic factors. BMC Cancer 2012 Feb;12:49.

13. Kim M, Na DL, Park SH, Jeon BS, Rah JK. Nervous system involvement by metastatic hepatocelular carcinoma. J Neurooncol 1998 Jan;36(1):85-90.

14. Choi HJ, Cho BC, Sohn JH, Shin SJ, Kim SH, Kim JH, Yoo NC. Brain metastases from hepatocellular carcinoma: prognostic factors and outcome: brain metastasis from HCC. J Neurooncol 2009 Feb;91(3):307-13

15. Uchino K. Tateishi R, Shiina S, Kanda M, Masuzaki R, Kondo Y, Goto T, Ornata M, Yoshida H,Koike K. Hepatocellular carcinoma with extrahepatic metastasis: Clinical features and prognostic factors. Cancer 2011 Oct;117(19): 4475-83.

16. Natsuizaka M. Omusa T, Akaike T, et al. Clinical features of hepatocellular carcinoma with extrahepatic metastases. J Gastroentero Hepatol 2005 Nov;20(11):1781-7. 
17. Fukutomi M, Yokota M, Chuman H, Harada H, Zaitsu Y, Funakoshi A, Wakasugi $\mathrm{H}$, Iguchi $\mathrm{H}$. Increased incidence of bone metastases in hepatocellular carcinoma. Eur $\mathrm{J}$ Gastroenterol Hepatol 2001 Sep;13(9):1083-8.

18. Barai S, Bandopadhayaya G, Chumber S, Haloi A, Seith A, Dhanapathi H, Kumar R, Malhotra A. Hepatocellular carcinoma presenting with pathological fracture of vertebra: report of a case. Eur J Radiology Extra 2004 Aug;51(2):73-6.

19. Golimbu C, Firooznia H, Rafii M. Hepatocellular carcinoma with skeletal metastasis. Radiology 1985 Mar; 154(3):617-8.
20. Liaw CC, Ng kT, Chen TJ, Liaw YF. Hepatocellular carcinoma presenting as bone metastasis. Cancer 1989 Oct 15;64(8):1753-7.

21. Raoul JL, Le Simple T, Le Prisé E, Meunier B, Ben Hassel $\mathrm{M}$, Bretagne JF. Bone metastasis revealing hepatocellular carcinoma: a report of three cases with a long clinical course. Am J Gastroenterol 1995 Jul;90(7):1162-4.

22. Yen FS, Wu JC, Lai CR, Sheng WY, Kuo BI, Chen TZ, Tsay SH, Lee SD. Clinical and radiological pictures of hepatocellular carcinoma with intracranial metastasis. J Gastoenterol Hepatol 1995; 10:413-8 